\title{
MEIO AMBIENTE DO TRABALHO E SAÚDE MENTAL: UMA INTEGRAÇÃO NECESSÁRIA À EFETIVAÇÃO DA GARANTIA CONSTITUCIONAL A UM AMBIENTE LABORAL SAUDÁVEL
}

\author{
Amanda Carolina Souza Silva ${ }^{117}$ \\ Saul Duarte Tibaldi ${ }^{118}$
}

Recebido em: 13/08/2018

Aprovado em: 07/11/2018

\begin{abstract}
RESUMO
$\mathrm{O}$ artigo através do método de pesquisa bibliográfico e documental investiga como o ordenamento jurídico pátrio tem tutelado os riscos à saúde mental dos trabalhadores, e consequentemente se tem conferido ou não aos seus jurisdicionados a efetividade da garantia constitucional a um ambiente laboral saudável. Para tanto propõe uma reflexão acerca da evolução do trabalho humano, da saúde da construção normativa sobre a qual se desenvolveu a tutela constitucional atual do meio ambiente, por conseguinte do meio ambiente do trabalho, e do direito à saúde. A proteção da saúde pode ser analisada a partir de duas dimensões: uma física e uma psíquica. Apesar dos adoecimentos mentais ocupacionais terem aumentado de forma significativa nas últimas décadas a tutela jurídica dos riscos psicossociais é irrisória se comparada com a tutela jurídica de outros riscos que podem ser encontrados no ambiente laboral. Conclui-se que é necessário não apenas a formulação de uma regulação mais específica e contemporânea sobre $\mathrm{o}$ tema, mas se verifica a emergência da proposição de medidas continuas e sistemáticas que subsidiem ações de vigilância em saúde de do trabalhador tanto pelas organizações de trabalho quanto pelo Estado, a fim de se efetivar a garantia dos trabalhadores desempenharem suas atividades em um ambiente integralmente saudável.
\end{abstract}

Palavras-chave: Meio ambiente do trabalho. Saúde Mental. Garantia Constitucional.

\section{INTRODUÇÃO}

\footnotetext{
${ }^{117}$ Mestranda em Direito pela Universidade Federal de Mato Grosso - UFMT. Pós-Graduada em Direito Penal pela Faculdade Damásio de Jesus.

118 Doutor e Mestre em Direito das Relações Sociais pela Pontifícia Universidade Católica de São Paulo PUC/SP. Professor adjunto na graduação e na pós-graduação na Universidade Federal de Mato Grosso - UFMT.
} 
A Constituição Federal de 1988 elevou o meio ambiente ao status de garantia fundamental, incluindo-o no rol de direitos metaindividuais (artigo 225, caput). O meio ambiente quanto bem jurídico tutelado pode ser enquadrado a partir de vários prismas. $\mathrm{O}$ presente estudo é voltado para análise dos aspectos e matizes do meio ambiente do trabalho, mormente da sua integração com a saúde mental dos trabalhadores como condição indissociável à efetiva garantia a um ambiente laboral hígido e equilibrado.

A qualidade do meio ambiente do trabalho possui uma relação intrínseca com todos os fatores naturais, técnicos e psicológicos que o constituem, bem como com a organização do trabalho, e isto reflete indubitavelmente na saúde física e mental do trabalhador. Dessa forma a proteção ao meio ambiente laboral visa tanto resguardar a saúde do trabalhador como garantir condições mínimas de dignidade para o desempenho do labor.

No cenário pós-moderno a mudança nas dinâmicas relacionais de trabalho, oriundas das alterações na estruturação da organização produtiva, como as novas formas de contratos de trabalho e emprego, a intensificação da atividade laboral, as elevadas exigências emocionais no trabalho e a falta de equilíbrio entre vida e trabalho, tem trazido implicações significativas na saúde mental dos trabalhadores.

A presente pesquisa objetiva investigar como o ordenamento jurídico pátrio tem tutelado os riscos à saúde mental dos trabalhadores, e consequentemente se tem conferido ou não aos seus jurisdicionados a efetividade da garantia constitucional a um ambiente laboral saudável.

Nesta linha de raciocínio, o presente trabalho, primeiramente aborda a evolução do trabalho humano, correlacionando o tema com o princípio da dignidade humana, conseguinte trata dos riscos no ambiente laboral com ênfase nos riscos psicossociais e na dimensão psíquica da saúde do trabalhador, depois analisa o meio ambiente sob enfoque constitucional e de direito fundamental. Por fim avalia o meio ambiente de trabalho, conceituando-o e destacando aspectos de integração entre o mesmo e a saúde mental como elementos necessários a garantia fundamental a um ambiente de trabalho saudável.

\section{O TRABALHO COMO DIREITO HUMANO FUNDAMENTAL}

O trabalho humano possui raízes que remontam as civilizações mais antigas da humanidade. Entretanto a gênese daquilo que hoje se denomina trabalho, se difere da origem 
da proteção normativa ao trabalho (ROCHA, 2013, p.99).

A presente pesquisa não visa exaurir todos os significados e dimensões que corroboraram para a construção do conceito pós-moderno de trabalho, mas busca abordar o tema a partir de algumas reflexões preliminares sobre o panorama histórico de origem desta importante relação que se consolidou como elemento indissociável da realidade social.

Por esta razão se faz basilar retomar alguns marcos históricos das relações de trabalho, como ponto inicial de compreensão do quadro que fez emergir a tutela jurídica do direito ao trabalho, até chegar ao seu reconhecimento atual como um direito econômico, social, cultural e sobretudo fundamental.

De acordo com os ensinamentos de Zimmer Knapik (2005) nas sociedades mais primitivas (tribais) já existia a ideia de trabalho, contudo, apenas um viés eminentemente coletivo estava relacionado à realização das atividades produtivas. Não havia uma divisão de trabalho, mas tão somente uma divisão de tarefas pelos critérios sexo e idade. A sobrevivência do grupo dependia do trabalho coletivo e este era voltado para as necessidades imediatas daquela sociedade comunal ou primitiva.

Passado o período das sociedades tribais o evento mais marcante nas relações de trabalho foi o surgimento do modo de produção tributária ou asiático, presente nas sociedades chinesa, egípcia, hebraica, fenícia, mesopotâmica, que se destacou por promover gradualmente a transição de uma sociedade sem classe (primitiva) para outra de classes, onde apesar de ainda não existir a propriedade privada, já existia a exploração do homem pelo homem (ZIMMER KNAPIK, 2005, p.99).

A partir da constituição do referido modelo de produção, verifica-se que o viés eminentemente coletivo, exclusivo nos modelos das sociedades comunais ou primitivas, passou a dar espaço a um modelo de organização que trabalho que não via mais nesse tipo de relação apenas uma questão de sobrevivência.

Posteriormente a partir da antiguidade clássica, Grécia e Roma passaram a constituir o cenário de surgimento de um novo modo de produção, o modo de produção escravista, onde o trabalho era visto na maioria substancial dos casos, como uma forma de penalidade. $\mathrm{Na}$ Grécia os escravos deveriam servir aos cidadãos por terem sido conquistados em batalha, e apesar de representarem a parte preponderante da população da época não eram vistos como seres humanos não possuindo qualquer direito, estavam condicionados ao status de mercadoria, sendo seu trabalho objeto de relações privadas. Neste período já existia um pequeno grupo que exercia atividades com autonomia, mas estas atividades eram equiparadas a prestações de serviços e nada mais (ZIMMER KNAPIK, 2005). 
Já em Roma o povo se dividia em patrícios (nobreza), plebeus (maioria livre, mas sem direitos políticos) e escravos (grande maioria prisioneiros de guerra, que formavam o grande contingente que sustentavam a sociedade romana). A forma de exploração do trabalho também era relacionada a uma penalidade, exercida por meio da força (ZIMMER KNAPIK, 2005, p.43).

Mister se faz destacar que a origem etimológica da palavra trabalho data do fim do século VI e se originou do latim tripalium, que pode ser entendido como uma espécie de instrumento de tortura, que era usado pelos romanos para compelirem os escravos e plebeus a trabalharem, ou seja, trabalho era sinônimo de sofrimento, e a gênese da terminologia já trazia sua carga. As relações socioeconômicas (inclusive as atividades desenvolvidas de forma autônoma) eram marcadas por profunda desigualdade, o que suscitou muitas lutas sociais que permitiram até certo tempo um nível de igualdade entre patrícios e plebeus. Com a queda do império romano este modo de organização societária foi dando espaço para o surgimento dos primeiros núcleos feudais (ZIMMER KNAPIK, 2005, p.43).

$\mathrm{Na}$ baixa idade média o modo de produção prevalente era o feudal baseado na servidão. O modo de produção feudal estava baseado em uma economia agrária, voltada para a subsistência. Apesar dos servos não serem considerados escravos, eram submetidos a condições similares, deveriam trabalhar gratuitamente, alguns dias na semana, nas terras do senhor e o pouco que produziam servia unicamente, e quando servia, para a sobrevivência, em troca da proteção concedida pelo senhor feudal. É relevante deixar claro que no feudalismo era praticamente impossível a ascensão social do trabalhador, uma vez que a sociedade feudal era compartimentada em estamentos sociais, ou seja, determinava quase sempre a colocação social de um indivíduo para o resto de sua vida.

No período de transição da baixa idade média para a alta idade média, houve início ao um processo de emancipação dos servos e de êxodo rural, em que muitas famílias que moravam nos feudos migravam para as cidades, fato que segundo Zimmer Knapik (2005), ensejou o início das corporações de ofício, ${ }^{119}$ que mantinham com os trabalhadores uma relação autoritária e uma preocupação muito mais comercial do que voltada à proteção dos interesses dos servos emancipados.

Em 1789 com o advento dos ideais de liberdade, igualdade, felicidade e fraternidade propagados pela Revolução Francesa, e a supressão das desigualdades entre indivíduos e

\footnotetext{
${ }^{119}$ Segundo Márcia Carneiro Zimmer Knapik, as corporações de ofício eram associações profissionais de defesa mútua, destinadas a proteger seus interesses e lutar contra a aristocracia, organizando as relações entre os mesmos e os servos emancipados, o público e o mercado, estipulando preços que fossem justos e não prejudiciais entre eles mesmos. (ZIMMER KNAPIK, 2005, p.51).
} 
grupos sociais, as corporações de ofício foram extintas por não se mostrarem compatíveis com os referidos ideais. Em 1791 a Lei Chapelier ${ }^{120}$ proibiu seu restabelecimento e demais coalizões (COMPARATO, 2003, p.81).

Na segunda metade do século XVIII emerge o liberalismo baseado no regime de livre realização e contratação de trabalho e fundamentado na prevalência da autonomia privada (ausência de intervenção estatal nestas relações), pelo crescimento do modo de produção capitalista. Neste quadro histórico a crescente industrialização originada na Inglaterra (Revolução Industrial), a ausência de qualquer tutela protetiva que visasse nivelar a desigualdade imensurável entre capital e trabalho, acrescida das condições inapropriadas e degradantes no locus de trabalho, que adoecia quando não matava os trabalhadores, intensificaram a reação contra os ideais da doutrina liberal, para exigir do estado uma intervenção estatal a fim colocar limites à autonomia plena do empregador e do empregado. É o período que marca a gênese do direito ao trabalho.

Sobre o tema Rocha (2013) assevera:

[...] Como resultado, são estabelecidas desde condições pré-contratuais à determinação de padrões mínimos no decorrer da relação laboral, na delimitação dos poderes de direção do empregador, no primado do contrato de trabalho como instrumento de regulação; enfim esta disciplina jurídica estrutura um complexo sistema de proteção aos direitos dos trabalhadores e ao uso da força de trabalho (ROCHA, 2013, p.43).

Desta forma impende afirmar que as relações de trabalho remontam a época mais pretérita da história das civilizações, contudo antes do desenvolvimento da sociedade industrial as normas jurídicas de Direito do Trabalho inexistiam. Foi a partir da Revolução Industrial que estas normas começaram a ser determinadas, pois o Estado interviu, e é a esse contexto que se pode atribuir o surgimento de um "direito ao trabalho", ou seja, o trabalho como liberdade e não mais como uma questão de sobrevivência ou de penalidade.

Contemporaneamente o direito ao trabalho é um direito humano fundamental, reconhecido como condição indispensável para outros direitos humanos e consagrado em diversos instrumentos jurídicos internacionais como a Declaração Universal dos Direitos Humanos (1948), ${ }^{121}$ o Pacto Internacional sobre os Direitos Econômicos Sociais e Culturais

\footnotetext{
${ }^{120}$ A Lei Chapelier de 1971 proibiu permanentemente o restabelecimento das corporações de ofício. Disponível em: <http://www.fafich.ufmg.br/hist_discip_grad/LeiChapelier.pdf >. Acesso em 12 jul de 2017.

121 ORGANIZAÇÃO DAS NAÇÕÉ UNIDAS (ONU). Declaração universal dos direitos humanos (1948). Disponível em: http://www.mj.gov.br/sedh/ct/legis_intern/ddh_bib_inter_universal.htm. 0 § $1^{\circ}$ do art.23 da Declaração Universal dos Direitos Humanos proclama: "Toda pessoa tem direito ao trabalho, à livre escolha de seu trabalho, a condições equitativas e satisfatórias de trabalho e à proteção contra o desemprego".
} 
(1967), a Constituição da OIT (1919), Protocolo adicional ao Pacto de San José da Costa Rica sobre Direitos Econômicos, Sociais e Culturais, além da legislação doméstica na Constituição Federal de $1998^{122}$.

\title{
3 A GÊNESE DA PROTEÇÃO À SAÚDE DO TRABALHADOR
}

A qualidade do ambiente laboral tem relação com a integridade ética, psíquica e física do trabalhador, por isso proteger este ambiente, zelando pela saúde do trabalhador, tem relação indissociável com a dignidade humana.

A Carta Magna alçou a matéria de proteção jurídica da saúde do trabalhador (segurança, higiene e medicina do trabalho) a matéria constitucional, considerando como direito social indisponível a execução das atividades laborais em ambiente seguro e salubre.

Um dos objetivos da República Federativa do Brasil consiste em promover o bem de todos (artigo $3^{\circ}$, inciso IV) da Constituição Federal, garantindo-se ainda no artigo $6^{\circ}$ o direito à saúde.

Alice Monteiro de Barros (2007) assevera:

\begin{abstract}
Quando se reconhece constitucionalmente o direito à saúde e ao ressarcimento de danos físicos, o que imediatamente se protege é a saúde como integridade psicofísica (art. $\left.7^{\circ}, \mathrm{XXII}\right)$. Além de constitucionalmente garantida ela é um direito fundamental. Até o século XIX, concebia-se a enfermidade como um fenômeno físico, mas atualmente ela é vista como um fenômeno psicossomático (BARROS,2007, p.1036).
\end{abstract}

Para se tentar compreender o que configura esse direito fundamental à saúde, é necessário verificar como foi, e como é contemporaneamente entendido o conceito de saúde, bem como seus reflexos no ambiente laboral.

Etimologicamente a palavra "saúde" se originou do latim "salus-utis", o que significa "estado de são" e ainda "salvação". Por muito tempo o conceito de saúde ficou adstrito a uma dimensão negativa, mas em 1946 o documento de constituição da Organização Mundial de Saúde 1946 propôs uma definição positiva e progressista de saúde não apenas como a ausência de doença, mas como a situação de perfeito bem-estar físico, mental e social (OLIVEIRA, 2011, p.143).

No ano de 2010 a OMS apresentou o conceito de local de trabalho saudável, como

$122 \mathrm{O}$ direito ao trabalho é garantido pela Constituição Federal em seu $6^{\circ}$ artigo no rol dos direitos sociais, do artigo $7^{\circ}$ ao $11^{\circ}$ estão previstos os principais direitos para os trabalhadores que atuam sob a lei brasileira assim como a Consolidação das Leis de Trabalho de 1943. 
sendo aquele em que os trabalhadores e os gestores colaboram para o uso de um processo de melhoria contínua da proteção e promoção da segurança, saúde e bem-estar de todos os trabalhadores.

A $8^{\mathrm{a}}$ Conferência Nacional de Saúde ${ }^{123}$ esclarece que o direito à saúde significa a garantia pelo Estado de condições dignas de vida e de acesso universal e igualitário às ações de serviço e promoção, proteção e recuperação de saúde em todos os seus níveis, levando ao desenvolvimento pleno do ser humano na sua individualidade.

$\mathrm{Na} 8^{a}$ Conferência Nacional de Saúde ainda consta que o direito á saúde não se materializa simplesmente pelo texto constitucional, mas pela adoção de políticas de saúde integradas com as demais políticas econômicas e sociais assegurando os meios que permitam efetiva-la.

A preocupação do legislador com a proteção da saúde ocupacional no Brasil, deu ensejo a Política Nacional de Saúde do Trabalhador do Ministério da Saúde, que visa à redução dos acidentes e doenças relacionadas ao trabalho, através das diretrizes da portaria Portaria $n^{\circ} 1.125$ de 6 de julho de 2005, também a criação da Renast - conjunto de estratégias voltadas a atenção integral da saúde dos trabalhadores - e dos Cerests responsáveis por realizar ações de prevenção, promoção, diagnóstico, tratamento, reabilitação e vigilância em saúde dos trabalhadores.

Assim pode - se constatar que a saúde do trabalhador é um bem social juridicamente tutelado a nível constitucional tanto em sua dimensão física quanto na psíquica, Atualmente há essa preocupação, e um nível de proteção normativo mínimo tanto a nível internacional quanto a nível interno da saúde do trabalhador, mas nem sempre foi assim ${ }^{124}$. Os romanos foram os primeiros a perceberem uma relação entre o trabalho e as doenças, mas o marco mais importante na história referente à saúde do trabalhador data de 1700, na Itália, quando o médico Bernardino Ramazzini publica a obra De Morbis Artificum Diatriba, traduzida para o português como "As doenças dos trabalhadores". Este livro abrange uma série de doenças de trabalhadores e as medidas de prevenção e tratamento. Constatou-se pela primeira vez, um nexo de causalidade entre as condições ambientais de trabalho e á saúde do trabalhador que era submetido a determinadas condições e riscos de trabalho.

A partir do mencionado marco começaram a surgir outros estudos que buscavam investigar as relações entre as doenças desenvolvidas pelos trabalhadores e as atividades por

\footnotetext{
${ }^{123}$ BRASIL. 8 a Conferência Nacional de Saúde - relatório final. Brasília: Ministério da Saúde, 1986.

${ }^{124}$ A Constituição Federal de 1988 inseriu, de forma inédita, o direito à saúde no rol dos direitos sociais. Nos textos constitucionais anteriores, somente os trabalhadores que contribuíam com a Previdência Social é que teriam direito de acesso à saúde pública.
} 
eles desenvolvidas, mas não havia neste período ainda normas de proteção à saúde do trabalhador.

Com o advento da Revolução Industrial o cenário das atividades laborais mudou, de eminentemente artesanal para o de linhas de produção industriais e isso causou graves problemas. $\mathrm{O}$ trabalhador estava totalmente desassistido. $\mathrm{O}$ aumento substancial da produção e da expansão do capitalismo aumentavam e em contrapartida a miséria, o inchamento das urbes causada pelo êxodo rural, o número de doentes, e os ambientes de trabalho agressivos e perigosos cresciam de maneira exponencial. Com a introdução da máquina a vapor do $\mathrm{Sr}$. Watt no ano de 1800 tem início à passagem do capitalismo mercantil para o capitalismo industrial e este crítico quadro social apenas piora.

A mão de obra das fábricas era constituída em sua maioria por mulheres e crianças que deveriam contar com a sorte para manter-se vivas. Naquela época sob a influência do liberalismo econômico e seu postulado do laisser faire, laissez passer $^{125}$, que via as relações de trabalho sob a égide dos mesmos postulados das relações privadas, os acidentes, as lesões e as enfermidades eram consequência e responsabilidade do próprio empregado.

As reações da opinião pública deram impulso à intervenção estatal no cenário desolador da época. Em 1802, o parlamento britânico aprovou a primeira lei de proteção aos trabalhadores, a Lei de Saúde e Moral dos Aprendizes estabelecia o limite de 12 horas de trabalho por dia, proibia o trabalho noturno, obrigava os empregadores a lavar as paredes das fábricas duas vezes por ano, e tornava obrigatória a ventilação do ambiente (OLIVEIRA, 2011, p.57).

Em 1.830, o industrial Robert Dernham preocupado com as péssimas condições de saúde de seus trabalhadores instituiu em suas empresas o serviço de medicina do trabalho. A presença do médico passa a ser necessária para evitar as saídas do empregado doente, que era tratado na própria empresa. E assim começa-se a se consolidar a medicina do trabalho primeira etapa na proteção da saúde do trabalhador (SILVA, 2008, p. 120-121)

Na sequência em 1.833, surge a "Factory Act", lei inglesa que pode ser considerada a mais eficiente até então no campo de proteção ao trabalhador, voltada para as empresas têxteis que proibia trabalho noturno aos menores de 18 anos; determinava idade mínima de 9 anos para o trabalho, sendo que um médico devia atestar que o desenvolvimento físico da criança correspondia à sua idade cronológica.

No ano de 1891, a Encíclica do papa Leão XIII, De Rerum Novarum, voltada para a

125 Tradução literal: Deixe ir, deixe passar. 
resolução dos problemas sociais por meio de uma ordem focada no ideal cristão, influencia legisladores e estadistas para o avanço da proteção social. A partir deste importante marco começaram a aparecer as primeiras leis de acidente de trabalho. A encíclica influenciou o reconhecimento do trabalho humano como integrante do conjunto mínimo de direitos inerentes a cada ser humano, os denominados "Direitos Humanos", considerados como de $2^{\mathrm{a}}$ geração ou dimensão (MOLINA, 2013, p.149).

Mister se faz destacar que o reconhecimento de direitos trabalhistas nos países europeus e a internacionalização do direito do trabalho se deu por fatores relacionados ao modelo de economia capitalista, uma vez que os as jornadas extenuantes de trabalho, os recorrentes acidentes de trabalho e a imensurável insatisfação pessoal dos trabalhadores refletiam no aumento dos custos da produção.

O direito do trabalho se consolidou a partir da Constituição Mexicana em 1917, sendo a primeira a consagrar direitos sociais dos trabalhadores em nível constitucional. Após isso, a Constituição alemã de Weimar em 1919, também alçou direitos trabalhistas ao patamar de direitos fundamentais.

Ademais as reinvindicações dos trabalhadores durante a primeira Guerra Mundial levaram a criar pelo tratado de Versalhes ${ }^{126}$ em 1919, a Organização Internacional do Trabalho $^{127}$, que tem consagrado como um dos seus objetivos a proteção dos trabalhadores contra doenças profissionais e acidentes de trabalho.

A última onda de medidas protetivas concernentes à saúde do trabalhador data da segunda guerra mundial, com a etapa da saúde ocupacional, e resulta da relação de impotência dos serviços de Medicina do Trabalho para lidar com os esforços de reconstrução do pósguerra que submetia os trabalhadores a cargas extenuantes de trabalho, jornadas demasiadamente elastecidas, doenças ocupacionais e acidentes de trabalho (DEJOURS, 2015, p. 24).

Posteriormente a referida etapa, a promulgação da Declaração Universal dos Direitos do Homem, de 1948, entre outros tratados, convenções e textos constitucionais, ratificaram e ampliaram ainda mais o mosaico protetivo social do ser humano, inclusive em suas relações

\footnotetext{
${ }^{126}$ André Araújo Molina pondera que o tratado de Versalhes, além de consagrar o Direito do Trabalho como ramo autônomo da ciência jurídica, dando-lhe autonomia legislativa, trouxe no seu artigo 427 diversos direitos, entre eles a jornada de oito horas, o repouso semanal remunerado, o salário mínimo, o direito sindical e a igualdade de salários de igual valor, planificando em toda a Europa os direitos sociais básicos dos trabalhadores (MOLINA, 2013, p.149).

127 Valerio de Oliveira Mazzuoli pondera que o antecedente que mais contribuiu para a formação do Direito Internacional dos Direitos Humanos foi a Organização Internacional do Trabalho, regulando sua condição no plano internacional, tendo em vista assegurar padrões mais condizentes de dignidade e de bem-estar social. (MAZZUOLI, Valerio de Oliveira, 2014, p.51).
} 
laborais.

Todo o processo referenciado é fruto de uma constelação de violações a direitos humanos, oriunda da forma de lidar com o trabalho do modo de produção capitalista e também de uma expansiva insatisfação popular que fez eclodir diversos movimentos sociais, o que possibilitou ressignificar o valor do trabalho, conceber o trabalho digno, e integrar sua efetivação com a proteção da saúde do trabalhador.

Sobre o valor do trabalho Lima (1947) leciona:

O trabalho, que merece ser qualificado de valor primacial na vida em comum, não é apenas o trabalho imposto como uma penalidade e praticado como uma servidão destinada apenas a matar a fome. É o trabalho, não apenas racional, livre ou habitual. É o trabalho fecundo. Essa é a nota final do conceito autêntico da vida ativa em sua perfeição (LIMA, 1947, p.60).

Ademais a dignificação do trabalho traz à luz a noção de que o sistema econômico seja ele qual for deve servir ás pessoas e não o contrário. Esta ideia tem como matriz filosófica a concepção de dignidade humana do filósofo alemão Immanuel Kant, onde o ser humano não pode ser empregado como meio para satisfação alheia, mas deve ser tomado como um fim em si mesmo, seja em face do Estado seja em face de particulares.

Em uma perspectiva contemporânea e multidimensional Ingo Sarlet (2007) assim define a Dignidade da Pessoa Humana:

[...] qualidade intrínseca e distintiva reconhecida em cada ser humano que o faz merecedor do mesmo respeito e consideração por parte do Estado e da comunidade, implicando complexo de direitos e deveres fundamentais que assegurem a pessoa contra todo e qualquer ato de cunho degradante e desumano, como venham a lhe garantir as condições existenciais mínimas para uma vida saudável, além de propiciar e promover sua participação ativa e co-responsável nos destinos da própria existência e da vida em comunhão com os demais seres humanos (SARLET, 2007, p.62).

A preocupação com saúde do trabalhador decorre da valorização do trabalho como objeto da tutela jurídica. Sebastião Geraldo de Oliveira leciona (2011):

O florescimento do direito à saúde do trabalhador é consequência desse enfoque mais dignificante do trabalho. A lei reflete o senso moral da sociedade e evolui em harmonia com as mudanças dos valores sociais, numa incessante e renovada procura da Justiça. O aprimoramento ético influencia, de imediato, no comportamento social, na produção legislativa, na interpretação das leis, tudo para não divorciar o mundo do Direito da realidade fática que lhe dá sustentação (oliveira, 2011, p, 138).

Sem dúvida a preocupação com a saúde e a qualidade de vida do trabalhador obteve significativo progresso no decorrer da história da humanidade, e isso possibilitou a construção de um arsenal normativo protetivo inquestionavelmente relevante para a efetivação do direito 
humano fundamental ao trabalho digno, mas ainda esta preocupação e as medidas tomadas estão voltadas com expressividade para os riscos ${ }^{128}$ que mais se mostraram evidentes no curso da história da construção da proteção normativa a saúde do trabalhador: riscos de acidentes, riscos ergonômicos, riscos físicos, riscos químicos e riscos biológicos.

Atualmente, sem demérito algum a pertinência do estudo envolvendo os riscos supraaludidos, faz-se necessário, em razão do objetivo do presente trabalho desvelar os aspectos e matizes dos riscos à saúde mental dos trabalhadores -os psicossociais, a fim de se demonstrar a necessária integração que deve existir entre a saúde mental e o ambiente laboral e não apenas entre saúde física e ambiente de trabalho, para a efetivação da garantia fundamental a um ambiente de trabalho saudável.

\section{OS RISCOS NO AMBIENTE DE TRABALHO}

A terminologia risco assumiu diversos significados ao longo da história. Surgiu no sentido de identificar a possibilidade de controle sobre determinados eventos que ainda não ocorreram, mas podem vir a acontecer. Nada obstante importa assinalar que o risco apesar de não ter um conceito unívoco, decorre de uma decisão humana.

O conceito de "sociedade de riscos" concebido pelo sociólogo alemão Ulrich Bech, exerce influência prestigiada nas ciências humanas e emerge associado ao conceito de modernização reflexiva, sendo definido como uma forma sistemática de lidar com perigos e inseguranças induzidas e introduzidas pela própria modernização (AREOSA; NETO, 2014 p.6).

O ser humano apesar de ter logrado conquistas significativas nas diversas áreas da ciência, não consegue exercer controle absoluto sobre todos os acontecimentos que exercem impacto na segurança de sua vida e de sua saúde. A sociedade de risco destaca a inatingibilidade de uma certeza absoluta sobre estes eventos, ante a ainda ineficiência para se detectar determinados riscos, o que se relaciona com o conceito de risco emergente de segurança e saúde no trabalho eis que pode ser entendido como qualquer risco ocupacional que é novo e está a aumentar.

O risco no trabalho está associado ao ambiente laboral e as atividades nele desenvolvidas. Segundo Julio Cesar de Sá da Rocha (2013, p.105) existe um processo de

${ }^{128}$ BRASIL. Portaria n 3.214 de 08 de junho de 1978 NR - 5. Comissão Interna de Prevenção de Acidentes. 
seletividade de risco, que é determinado por aqueles que possuem os meios de produção, levando-se em conta componentes ambientais, a performance de trabalho e as próprias relações humanas.

Os riscos em suas diferentes dimensões está presente em quaisquer atividades laborais, por essa razão todos os polos da relação de trabalho e o Estado devem procurar formas de evitar ou ao menos minimizar os perigos produzidos no processo avançado de modernização.

Os riscos no ambiente laboral podem ser classificados em cinco tipos de acordo com a Portaria $n^{\circ} 3214 / 1978$ do Ministério do Trabalho do Brasil, quais sejam: riscos de acidente; riscos ergonômicos; riscos físicos; riscos químicos e riscos biológicos. A referida portaria não prevê a regulamentação dos riscos psicossociais.

Importa consignar que quando o risco do ambiente é conhecido, deve-se preveni-lo, mas mesmo quando o risco é incerto, a precaução determina evita-lo. O princípio da precaução e da prevenção representam um dos elementos mais importantes da disciplina normativa do ambiente do trabalho (WANDELLI, 2012, p. 278).

Mister se faz destacar a dimensão de seletividade da exposição ${ }^{129}$ a determinados riscos de algumas categorias, que em razão da desigualdade social, são submetidas de forma mais intensa e/ou continuada a determinadas substâncias e situações no ambiente laboral.

As doenças ocupacionais e os acidentes de trabalho são resultantes diretamente do trabalho desempenhado e/ou sob as condições em que são realizados, são resultados da exposição a determinados riscos.

Julio Cesar de Sá da Rocha (2013) assevera:

Os riscos potenciais da área ocupacional envolvem agentes químicos, e .g., gases, vapores, poeiras e líquidos; agentes físicos, e. g., extremas temperaturas, radiação, vibração, choques elétricos; agentes mecânicos, e g., defeitos no equipamento e inadequada proteção da maquinaria; repetição de movimentos e inadequada postura no trabalho; agentes psicológicos, e g., controle excessivo e pressão intensa sobre o trabalhador (rocha, 2013,p.105).

Necessário ainda se faz acrescer aos riscos supracitados, o risco biológico, decorrente da exposição a agentes - vírus, bactérias, parasitas, protozoários, fungos e bacilos - que dependendo da forma de contato podem causar doenças no ser humano.

Assim pode-se afirmar que diversos tipos de riscos - químicos; físicos, mecânicos, psicossociais coexistem com maior ou menor frequência no ambiente de trabalho, cabe agora verificar alguns aspectos dos riscos que mais tem atingido a saúde psíquica dos trabalhadores

\footnotetext{
${ }^{129}$ Sobre o tema ler BAUMAN, Zygmunt Danos Colaterais: desigualdades sociais numa era global; tradução
} Carlos Alberto Medeiros. Rio de Janeiro:Zahar, 2013. (BAUMAN, ZYGMUNT, p.15). 
e crescido de forma exponencial no contexto laborativo - os riscos psicossociais.

Os riscos psicossociais relacionados ao trabalho são indubitavelmente uma das ameaças mais graves à saúde do trabalhador. Apesar de serem contemporâneos à origem do próprio trabalho, têm se destacado como um dos riscos emergentes mais preocupantes na sociedade pós-moderna.

As mudanças na estruturação organizacional do trabalho, as novas formas de contratos de trabalho e emprego, o envelhecimento da população ativa, a intensificação da atividade laboral, as elevadas exigências emocionais no trabalho e a falta de equilíbrio entre vida e trabalho são causadas atribuídas ao aumento dos riscos psicossociais (AREOSA; NETO, 2014, p.10).

No Brasil se verifica que o afastamento por transtornos mentais superior a 15 dias ocupa o terceiro lugar na lista de pagamento por benefícios da Previdência Social, segundo estatística do Instituto Nacional de Previdência Social. ${ }^{130}$

O Instituto Sindical de Trabajo Ambiente y Salud (ISTAS) 2014 conceitua os riscos psicossociais:

riscos psicossociais são condições de trabalho derivadas da organização do trabalho de condições de trabalho, para o qual ele pode ser mostrado que prejudicam a saúde dos trabalhadores e das trabalhadoras. PSICO porque eles nos afetam através da psique (conjunto de ações e funçõesmente) e social porque sua origem é social: certas características da organização do trabalho (ISTAS, 2014, p.17). ${ }^{131}$

Ademais o (ISTAS) 2014 define os fatores psicossociais como aquelas características das condições de trabalho e, sobretudo, da sua organização que afetam a saúde das pessoas através de mecanismos psicológicos e fisiológicos a que também chamamos de stress. $\mathrm{O}$ referido instituto ainda identifica quadro divisões de tais fatores: $\mathrm{O}$ excesso de exigências psicológicas no trabalho; a falta de influência e de autonomia no desenvolvimento do trabalho; a falta de suporte social e a baixa qualidade de liderança e ainda apouca compensação de trabalho.

Baruki (2016, P.37-38) aclara o conteúdo das seis categorias de fatores psicossociais

\footnotetext{
${ }^{130}$ BRASIL, Auxílios-doença acidentários e previdenciários concedidos segundo os códigos da Classificação Internacional de Doenças - CID-10. Disponível em: <http://www.previdencia.gov.br/dadosabertos/estatsticas/tabelas-cid-10/>. Acesso em 02 de out.2016.

${ }^{131}$ INSTITUTO SINDICAL DE TRABAJO AMBIENTE E SALUD (ISTAS). Organización del trabajo, salud y riesgos psicosociales: Guia para la intervención sindical em organización de trabajo e riesgos psicosociales. Disponível em: <http://www.istas.ccoo.es/descargas/GUIA\%20azul\%20psicosociales\%2020150.pdf〉, Tradução livre de: "Los riesgos psicosociales son condiciones de trabajo derivadas de la organización del trabajo, para las que se puede demostrar que perjudican la salud de los trabajadores y las trabajadoras. PSICO porque nos afectan a través de la psique (conjunto de actos y funciones de lamente) y SOCIAL porque su origen es social: determinadas característicasde la organización del trabajo”. p. 17. Acesso em 12 agosto de 2017.
} 
do trabalho descritas pela da OIT: sobrecarga quantitativa - pode ser entendida como multiplicidade de afazeres sobre pressão ou ainda muito trabalho repetitivo; carga qualitativa insuficiente - refere ao trabalho limitado e não instigante; o conflito de papéis e funções ausência de determinação de função pelo indivíduo; a falta de controle sobre a situação verifica-se quando o trabalhador não recebe comando diretivo sobre a forma e o tempo de execução do seu trabalho; a falta de apoio social - se configura como a ausência de estímulo ou reconhecimento no trabalho ou no ambiente familiar; os estressores físicos - se referem a fatores que podem afetar o trabalhador física e quimicamente

Os fatores psicossociais são inerentes ao ser humano, e segundo Dejours (2015), cada indivíduo irá responder de forma singular, quando submetido a algum destes riscos, podendo ter seus efeitos minimizados ou maximizados, a depender de sua estrutura psíquica e de sua personalidade, o que demonstra a diversidade humana.

Os riscos psicossociais apesar de aturem na dimensão psíquica da saúde do trabalhador, existem, e se não prevenidos ou elididos podem minar gravemente a saúde do trabalhador, levando-o até mesmo ao óbito, seja pelo impulso de desenvolvimento de um transtorno mental, ou pela somatização do sofrimento, ou pelo suicídio. O direito a um meio ambiente saudável engloba a proteção da saúde, por esta razão a tutela normativa da saúde no ambiente de trabalho deve ser voltada para a proteção do trabalhador na sua integralidade.

\section{O MEIO AMBIENTE COMO GARANTIA CONSTITUCIONAL}

A lei 6.938/81, que estatui a Política Nacional do Meio Ambiente (PNMA), conceituou o meio ambiente como sendo o "conjunto de condições, leis, influências e interações de ordem física, química e biológica, que permite, abriga e regra a vida em todas as suas formas".

Apesar da Constituição Federal não ter definido meio ambiente, recepcionou o conceito extraído da Política Nacional do Meio ambiente ao classificar o meio ambiente como um "bem de uso comum do povo e essencial à sadia qualidade de vida". O aludido conceito apesar de abranger apenas o meio ambiente natural, foi ampliado pela doutrina para incluir o ambiente natural, artificial, cultural e do trabalho.

$\mathrm{O}$ direito fundamental ao meio ambiente sadio e equilibrado encontra-se disposto no artigo 225 da Carta Magna: 
Todos têm direito ao meio ambiente ecologicamente equilibrado, bem de uso comum do povo e essencial á sadia qualidade de vida, impondo-se ao Poder Público e à coletividade o dever de defende-lo para as presentes e futuras gerações. ${ }^{132}$

Como se recolhe do referido dispositivo constitucional o meio ambiente é caracterizado como bem de uso comum do povo, pertencente a toda coletividade, incorpóreo, indivisível, insuscetível de apropriação exclusiva, intergeracional e supraindividual, cujos danos são de difícil ou impossível reparação (BAHIA: et al, 2015, p.41).

$\mathrm{O}$ meio ambiente é um direito difuso ${ }^{133}$ de terceira geração ${ }^{134}$. Consigna-se que uma sequência de gerações de direito não exclui a outra. A ideia é a de que esses direitos se complementam e se conjugam e não se cindem em "gerações" ou "dimensões" por serem indivisíveis (MAZZUOLI, 2014, p.27).

Outrossim o meio ambiente ecologicamente equilibrado deve ser buscado através da conciliação do binômio desenvolvimento e ambiente. Luís Paulo Sirvinkas (2016) ensina:

Compatibilizar meio ambiente e desenvolvimento significa considerar os problemas ambientais dentro de um processo contínuo de planejamento, atendendo-se adequadamente as necessidades de ambos e observando-se as suas inter-relações particulares a cada contexto sociocultural, político econômico e ecológico dentro de uma dimensão tempo/espaço (Sirvinkas, 2016, 162)

Ante o exposto é possível extrair a ideia de que as políticas ambientais não devem ser um óbice ao desenvolvimento, mas ser um elemento de interação integrativa a fim de propiciar uma melhor gestão dos recursos naturais e do uso saudável do meio ambiente.

Além do que, apesar de ter sido incluído na categoria "bem de uso comum do povo", o meio ambiente não pode ser considerado como algo público ou privado, uma vez que é considerado como pertencente a toda coletividade. A preservação desta garantia fundamental deve ser objetivo não apenas do Estado, mas também dos particulares da presente e das futuras gerações.

A maioria das Constituições ocidentais passou a proteger o meio ambiente como garantia da coletividade, na medida em que depende da qualidade do meio ambiente não somente as condições, mas a própria sobrevivência da vida humana, e a Constituição Federal de 1988, não o fez de forma diferente, elevou o meio ambiente ao status de garantia fundamental, incluindo-o no rol de direitos metaindividuais.

\footnotetext{
132 BRASIL. Constituição (1988). Constituição da República Federativa do Brasil. Brasília, DF: Senado Federal: Centro Gráfico, 1988.

133 Os interesses difusos são aqueles transindividuais, de natureza indivisível, de que sejam titulares pessoas indeterminadas e ligadas por circunstância de fato (BAHIA: et al, 2015, p.42).

${ }^{134} \mathrm{Em}$ face de sua metaindividualidade o direito a um ambiente equilibrado é um direito de terceira geração, na qual se destaca à fraternidade e à solidariedade buscando a universalização de todos os direitos (BAHIA: et al, 2015, p.42).
} 
No ordenamento jurídico brasileiro, a partir de uma análise literal, os direitos fundamentais podem ser compreendidos como aqueles de forma explícita ou tácita receberam a proteção Constitucional José Joaquim Gomes Canotilho (2003) define direitos fundamentais “como sendo aqueles direitos dos homens, jurídico-institucionalmente garantidos e limitados tempo espacio-temporalmente" (CANOTILHO, 2003, p.393)

Segundo Melo (2010, p.15) há dois objetos de tutela ambiental: um imediato, referente à qualidade do meio ambiente em todas suas dimensões e aspectos e outro imediato, concernente a saúde, segurança e bem-estar do cidadão.

O princípio $1^{\circ}$ da Declaração da Conferência de ONU no Ambiente Humano (Conferência de Estocolmo) de 1972 reconhece o meio ambiente sadio como direito fundamental.

O homem tem o direito fundamental à liberdade, à igualdade e ao desfrute de condições de vida adequadas em um meio ambiente de qualidade tal que lhe permita levar uma vida digna e gozar de bem-estar, tendo a solene obrigação de proteger e melhorar o meio ambiente para as gerações presentes e futuras ${ }^{135}$

A primeira função dos direitos fundamentais é a defesa da pessoa humana e da sua dignidade no plano tanto da eficácia horizontal, quanto da eficácia vertical. Quanto à função dos direitos fundamentais José Joaquim Gomes Canotilho ensina:

\footnotetext{
Os direitos fundamentais cumprem a função de direitos de defesa dos cidadãos, sob uma dupla perspectiva: constituem, num plano jurídico-objectivo, normas de competência negativa para os poderes públicos, proibindo fundamentalmente as ingerências destes na esfera jurídica individual; implicam num plano jurídicosubjectivo, o poder de exercer positivamente direitos fundamentais (liberdade positiva) e de exigir omissões dos poderes públicos, de forma a evitar agressões lesivas por parte dos mesmos (liberdade negativa). (canotilgo, 2003, P, 407)
}

Com isso pode se verificar que ao tutelar o meio ambiente em todos os seus prismas como um direito fundamental, o Estado impõe a si e aos cidadãos diretrizes para condutas comissivas ou de abstenção que visem tutelar este bem jurídica que independente de sua dimensão tem relação indissociável com qualidade de vida e a própria dignidade da pessoa humana.

\section{MEIO AMBIENTE DO TRABALHO}

\footnotetext{
135 Direitos Humanos na Internet. Declaração de Estocolmo sobre o meio ambiente humano - 1972. Disponível em: http://www.dhnet.org.br/direitos/sip/onu/doc/estoc72.htm. Acesso em 11 jul de 2017.
} 


\title{
6.1 Conceito
}

O meio ambiente do trabalho pode ser conceituado como o conjunto de fatores endógenos e exógenos, que agem de forma isolada ou cumulada, sob o trabalhador no desempenho de suas atividades laborais e que impactam sua saúde física e mental.

O doutrinador Amauri Mascaro do Nascimento (1999) conceitua:

[...]o meio ambiente de trabalho é, exatamente, o complexo máquina-trabalho; as edificações, do estabelecimento, equipamentos de proteção individual, iluminação, conforto térmico, instalações elétricas, condições de salubridade ou insalubridade, de periculosidade ou não, meios de prevenção à fadiga, outras medidas de proteção ao trabalhador, jornadas de trabalho e horas extras, intervalos, descansos, férias, movimentação, armazenagem e manuseio de materiais que formam o conjunto de condições de trabalho etc (Nascimento 1999, p.584).

Outrossim Rocha (2013) define meio ambiente do trabalho como:

\begin{abstract}
Soma das influências que afetam diretamente o ser humano, desempenhando aspecto chave na prestação e performance de trabalho. Pode-se, simbolicamente, afirmar que o meio ambiente de trabalho constitui o pano de fundo das complexas relações biológicas, psicológicas e sociais a que o trabalhador está submetido 9rocha, 2013, p.99).
\end{abstract}

Ainda Maranhão (2016) entende o meio ambiente do trabalho da seguinte forma:

[...] a nosso sentir, juridicamente, meio ambiente do trabalho é a resultante da interação sistêmica de fatores naturais, técnicos e psicológicos ligados às condições de trabalho, à organização do trabalho e às relações interpessoais que condiciona a segurança e a saúde física e mental do ser humano exposto a qualquer contexto jurídico-laborativo (MARANHÃO, 2016, p. 3)

A proteção constitucional do meio ambiente laboral tutela não só a dignidade do trabalhador, mas a humanização do próprio trabalho, transcendendo as preocupações de ordem meramente econômicas em detrimento da construção da qualidade de vida, do bemestar, da identidade e de dignidade de quem trabalha.

Os efeitos das atividades desenvolvidas no meio ambiente laboral suplantam a esfera de trabalho atingindo diretamente as demais áreas de convivência e à qualidade de vida dos trabalhadores, principalmente a saúde mental (ANTUNES, 2004).

Barros pontua que no meio ambiente do trabalho, o bem jurídico tutelado é a saúde do trabalhador, que deve ser resguardada de toda forma de poluição do meio ambiente laboral, a fim que desfrute de qualidade de vida saudável e vida com dignidade (BARROS, 2007, p.1050).

O meio ambiente do trabalho é o local onde o indivíduo passa a maior parte dos seus 
dias, na maioria das vezes a maior parte de sua vida, e é elementar que tenha condições de salubridade e higidez apropriadas tanto para que o trabalhador possa exercer com boas condições físicas e psíquicas suas atividades laborais, quanto para que possa gozar de saúde e de qualidade de vida.

A proteção constitucional ao meio ambiente de trabalho é voltada para a busca das causas do adoecimento ocupacional e da criação de medidas protetivas voltadas a elidir os riscos identificáveis no locus de trabalho.

Os artigos $6^{\circ}, 7^{\circ}$, XXII, 196 a 200 e art. $225, \S 1^{\circ}, \mathrm{V}$, da Constituição da República evidenciam que a saúde do trabalhador e o meio ambiente do trabalho foram alçados a direito social de natureza constitucional, e cujo cumprimento é imposto por lei ao empregador, conforme se verifica dos arts. 154 a 201 da CLT (com redação dada pela Lei 6.514/77) e Portarias 3.214/78 e 3.067/88, do Ministério do Trabalho e Emprego, que regulamentam segurança e medicina do trabalho urbano e rural.

Em nível internacional aplicável ao meio ambiente de trabalho, o Brasil ratificou as Convenções 81, 148, 152, 155 e 161, da OIT. A convenção 81, que trata da inspeção no trabalho na indústria e no comércio, foi ratificada em 25 de abril de 1957 e promulgada através do Decreto $n^{\circ} 41.721$, de 25.6.57. A Convenção 148, que trata da contaminação do ar, ruído e vibrações, foi ratificada em 14.01 .82 e promulgada através do Decreto $\mathrm{n}^{\circ}$ 93.413, de 15.10.86. A Convenção 152, que trata da segurança e higiene dos trabalhos portuários, foi ratificada em 17.05.90 e promulgada pelo Decreto $\mathrm{n}^{\circ}$ 99.534, de 19.09.90. A Convenção 155, que trata da segurança e saúde dos trabalhadores, foi ratificada em 18.05 .92 e promulgada pelo Decreto $n^{\circ} 1.254 / 94$. A Convenção 161 , que trata dos serviços de saúde do trabalho, foi ratificada em 18.05.90 e promulgada através do Decreto $n^{\circ} 127$, de 22.05.91.

A salubridade, a higidez e o equilíbrio do meio ambiente de trabalho devem ser tutelados pelo Estado e se configurar como obrigação preferencial do empregador, e ser efetivada através de seu poder de gestão, de organização e de fiscalização, que instrui, informa e fiscaliza o ambiente de trabalho a fim de se prevenir doenças ocupacionais e acidentes de trabalho.

6.2 Meio ambiente de trabalho e saúde mental

No ambiente de trabalho vários riscos coexistem e influem na saúde do trabalhador de forma direta ou indireta. Levando em consideração que o direito à saúde e ao meio ambiente de trabalho são direitos fundamentais, é obrigação do Estado realizar a proteção do 
trabalhador em todas suas dimensões, sobretudo no que tange à saúde mental do trabalhador eis que ainda é a área que mais carece de Normas Regulamentadoras atinentes a prevenção dos riscos psicossociais.

A omissão do Estado abre margem para o fenômeno denominado "ativismo judicial", na medida em que a ausência de legislação elastece sobremaneira a discricionariedade do poder judiciário, afetando a uniformidade das decisões e por conseguinte a própria segurança jurídica.

O mosaico normativo brasileiro em relação aos riscos psicossociais no ambiente de trabalho necessita ser ampliado. Os princípios da prevenção e da precaução apesar de serem indiscutivelmente importantes carecem de normas concretas. A norma regulamentadora $\mathrm{n}^{\circ}$ $17^{136}$ trata da adequação entre às características psicofisiológicas dos trabalhadores e à natureza do trabalho a ser executado. O Decreto $\mathrm{n}^{\circ}$ 3.048/99 - que regulamenta a previdência social- é o único instrumento normativo que trata dos Transtornos Mentais e do Comportamento Relacionados com o Trabalho, mesmo assim trata do sofrimento psíquico já em curso, não trata dos aspectos preventivos dos ricos psicossociais. A norma regulamentadora $\mathrm{n}^{\circ} 9$, que trata dos riscos ambientais, não trata dos riscos psicossociais.

Ao mostra-se silente quanto aos aspectos preventivos da proteção da saúde mental do trabalhador o Estado falha no dever fundamental de garantir um ambiente laboral saudável

Dejours (2015) defende a constituição de espaços de discussão no próprio local de trabalho:

[...] Estes espaços de discussão não seriam exatamente destinados a fazerem emergirem os problemas pessoais dos profissionais, ou seja, problemas ligados aos seu sofrimento singular, sua própria capacidade de manter seu equilíbrio mental ou somático. Os problemas a serem abordados nestes espaços de discussão diriam respeito à arbitragem em matéria de organização do trabalho de tratamento.(DEJOURS, 2015, p.220-222).

Levando em consideração que a saúde mental sofre impactos do modo organizacional do trabalho a referida proposta é uma alternativa que possibilitará aos próprios trabalhadores identificarem os aspectos a serem melhorados no ambiente organizacional, bem como traçar estratégias de natureza coletiva e individual para se prevenir dos riscos reconhecidos.

\footnotetext{
${ }^{136} \mathrm{O}$ item 6. 2 da NR 17, prevê que $\mathrm{O}$ treinamento deve conter noções sobre prevenção e os fatores de risco para a saúde, decorrentes da modalidade de trabalho de operador de checkout, levando em consideração os aspectos relacionados a: a) posto de trabalho; b) manipulação de mercadorias; c) organização do trabalho; d) aspectos psicossociais do trabalho e) agravos à saúde mais encontrados entre operadores de checkout.
} 


\section{CONSIDERAÇÕES FINAIS}

A história do trabalho humano mostra que o processo social que culminou na vindicação de melhores condições de trabalho teve gênese na exigência de melhores condições no ambiente laboral e de aspectos relacionados à proteção da saúde do trabalhador.

O direito de dispor de condições seguras e saudáveis no ambiente laboral mais do que proporcionar um padrão de vida adequado ao trabalhador, é condição indissociável da dignidade da pessoa humana. Apesar da forma de organização do trabalho não poder ser considerada como fonte de doença mental, incide diretamente no sofrimento psíquico dos trabalhadores.

A proteção dos trabalhadores contra doenças ocupacionais, independentemente de sua dimensão (física ou mental), é um direito humano fundamental, entretanto o aspecto psíquico, ainda é preterido, ou desvalorizado pelo constructo normativo protetivo da saúde do trabalhador.

Os riscos psicossociais são riscos emergentes, dinâmicos e contemporâneos. O direito necessita a partir dos inúmeros fatos sociais envolvendo violações a dimensão psíquica dos trabalhadores nos ambientes laborais, reconhecer a existência dos mesmos, ampliar o panorama normativo-protetivo e incentivar através de políticas públicas de prevenção e esclarecimento a desmitificação desta dimensão da saúde que fica subjugada ao pré-conceitos histórico-sociais ou ao limbo da ignorância de grande parte da população.

Cumpre, destacar a necessidade de medidas continuas e sistemáticas que subsidiem ações de vigilância em saúde mental, tal como a promoção de debates nos ambientes organizacionais sobre o problema da saúde mental, voltados precipuamente para a prevenção dos riscos psicossociais. Outrossim o trabalhador em estado de sofrimento psíquico deve receber todo o aparato necessário a fim de restabelecer sua saúde, tal qual teria, se fosse acometido de uma moléstia física, e isto passa por um processo de desconstrução de preconceitos e estigmas, de raízes socioculturais, que são afetos a grande parte da sociedade.

O Estado mostra-se silente quando é omisso quanto à relação entre a organização do trabalho e o aparelho mental dos trabalhadores. A integração do ambiente de trabalho e da saúde mental é indispensável não apenas para a garantia de um meio ambiente laboral saudável, mas para proteção integral do direito ao trabalho digno.

\section{REFERÊNCIAS}


ANTUNES, Paulo de Bessa. Direito Ambiental. 7. ed. Rio de Janeiro: Editora Lumen Juris, 2004.

ARENDT, Hannah. A condição humana. Tradução. Roberto Raposo. 13. ed. Rio de Janeiro: Forense Universitária, 2017.

AREOSA, João; NETO, Hernâni Veloso. MANUAL SOBRE RISCOS PSICOSSOCIAIS NO TRABALHO. Sociedade dos Riscos emergentes. Coleção Ricot, Civeri publishing, 2014.

Disponível em:

https://repositorium.sdum.uminho.pt/bitstream/1822/29932/1/Sociedade\%20dos\%20riscos\%2 0emergentes $\% 20 \% 28$ cap $\% 201 \% 29 \% 20-\% 20$ Areosa\%20e\%20Neto.pdf.> Acesso em 12 ago 2017.

BARUKI, Luciana Veloso. Riscos Psicossociais e a saúde mental do trabalhador: por um regime jurídico preventivo. São Paulo: Editora LTr, 2015.

BAHIA, Carolina Medeiros et al. Coordenador José Rubens Morato Leite. Manual de Direito AMBIENTAL. São Paulo. Saraiva, 2015.

BRASIL. Secretaria de Direitos Humanos da Presidência da República. Direito a um trabalho com dignidade. - Brasília: Coordenação Geral de Educação em SDH/PR, Direitos Humanos, Secretaria Nacional de Promoção e Defesa dos Direitos Humanos, 2013.

Auxílios-doença acidentários e previdenciários concedidos segundo os códigos da Classificação Internacional de Doenças - CID-10. Disponível em: http://www.previdencia.gov.br/dados-abertos/estatsticas/tabelas-cid-10/. Acesso em 02 de out.2016.

Constituição (1988). Constituição da República Federativa do Brasil. Brasília, DF: Senado Federal: Centro Gráfico, 1988.

Portaria no 3.214 de 08 de junho de 1978 NR - 5. Comissão Interna de Prevenção de Acidentes. In: SEGURANÇA E MEDICINA DO TRABALHO.

. Consolidação das Leis do Trabalho. Disponível em: . Acesso em 12 jul 2017.

BARROS, Alice Monteiro de. Curso de Direito do Trabalho. 3. ed. ver. e ampl. São Paulo: LTr, 2007. 
CANOTILHO, J.J.Gomes. Direito Constitucional e teoria da constituição. 7. ed. 17 reimp. Coimbra: Editora Almedina, 2003.

COMPARATO, Fábio Konder. A afirmação histórica dos direitos humanos. 3. ed., rev. e atual. São Paulo: Saraiva, 2003.

DEJOURS, Cristophe. A Loucura do Trabalho: Estudo de Psicopatologia do Trabalho. 6.ed. São Paulo: Cortez-Oboré, 2015.

. A banalização da injustiça social. 7. ed. Rio de Janeiro: Editora FGV, 2007.

INSTITUTO SINDICAL DE TRABAJO AMBIENTE E SALUD (ISTAS). Organización del trabajo, salud y riesgos psicosociales: Guia para la intervención sindical em organización de trabajo e riesgos psicosociales. Disponível em: $<$ http://www.istas.ccoo.es/descargas/GUIA\%20azul\%20psicosociales\%2020150.pdf>. Acesso em 12 ago de 2017.

FERNANDES, Fábio. Meio ambiente geral e meio ambiente do trabalho: uma visão sistêmica. São Paulo. LTr, 2009.

FIGUEIREDO, Guilherme José Purvin. Direito Ambiental e a saúde dos trabalhadores. São Paulo, Editora: LTDA, 2000.

GARCEZ, Gabriela Soldano. Do direito fundamental ao ambiente de trabalho equilibrado. Revista de Direitos Fundamentais e Democracia, Curitiba, v. 10, n. 10, p. 314-339, jul./dez. 2011.

JÚNIOR, Antônio Braga da Silva; FILHO, Roberto Freitas. A Fundamentalidade dos Direitos Trabalhistas: uma Diretriz Constitucional ainda pendente. Revista Constituição e Garantia de Direitos, vol. 9, n.2, p. 40-65, ago.2017.

KANT, Immanuel. Crítica da razão pura e outros textos filosóficos. Coleção Os Pensadores. Trad. Paulo Quintela. São Paulo: Abril Cultural, 1974.

KARASEK, Robert. Healthy work: stress, productivity, and the reconstruction of working life. Published by Basic Books, 1990.

Lei le Chapelier (1971). Disponível em: <http://www.fafich.ufmg.br/hist_discip_grad/LeiChapelier.pdf z. Acesso em 12 jul de 2017. 
LIMA. Alceu Amoroso Lima. O problema do trabalho. Rio de Janeiro. Livraria Agir Editora, 1947.

MATOS, Simão da Silva. Riscos Psicossociais em Trabalhadores na Arábia Saudita. Dissertação (Mestrado em Segurança e Higiene no Trabalho) - Instituto Politécnico de Setúbal. Setúbal, 2014. Disponível em: <https://comum.rcaap.pt/bitstream/10400.26/8202/1/Tese\%20-\%2024-02-2015.pdf>. Acesso em 30 jul de 2017.

MARANHÃO, Ney. Meio ambiente do trabalho: Descrição jurídico-conceitual. Revista Direitos, Trabalho e Política Social, v. 2, n. 3, jul./dez. 2016.

MAZZUOLI, Valerio de Oliveira. Curso de direitos humanos. São Paulo: Método, 2014.

MENDES, Ana Magnólia Bezerra.Aspectos psicodinâmicos da relação homem-trabalho: as contribuições de C. Dejours. Revista Psicologia: Ciência e Profissão, 1995, vol.15, n.1-3, pp.34-38. ISSN 1414-9893. Disponível em <http://dx.doi.org/10.1590/S141498931995000100009>.Acesso em 01 maio de 2017.

MINISTÉRIO DO TRABALHO E EMPREGO. NR9 - Programa de Prevenção de Riscos Ambientais. Disponível em <http://www.mte.gov.br/legislacao/normas_regulamentadoras/nr_09_at.pdf>. Acesso em 29 março de 2017.

MOLINA, André Araújo. Teoria dos Princípios Trabalhistas: a aplicação do modelo metodológico pós-positivista ao direito do trabalho. São Paulo. Editora Atlas, 2013.

NASCIMENTO, Amauri Mascaro do. A defesa processual do meio ambiente do trabalho. Revista LTr. São Paulo, ano 63, nº 5, pp. 583-587, maio 1999.

NOGUEIRA, Sandro D'Amato. Meio ambiente do trabalho: o princípio da prevenção ambiental. São Paulo: LTr, 2008.

OLIVEIRA, Sebastião Geraldo de Oliveira. Proteção Jurídica à Saúde do Trabalhador. 6. ed.rev.e atual. São Paulo: LTR, 2011.

(ONU) ORGANIZAÇÃO DAS NAÇÕES UNIDAS. Declaração universal dos direitos humanos (1948). Disponível em: 
<http://www.mj.gov.br/sedh/ct/legis_intern/ddh_bib_inter_universal.htm.>. Acesso em: 20 julho de 2017.

Declaração de Estocolmo sobre o Meio Ambiente Humano. In: Anais Conferência das Nações Unidas sobre Meio Ambiente Humano. Estocolmo, 1972. Disponível em: <http://www.dhnet.org.br/direitos/sip/onu/doc/estoc72.htm|>. Acesso em 11 jul 2017. ROLO, JOÃO CARVALHO. Sociologia da Saúde e da Segurança no Trabalho, IV Congresso Português de Sociologia. Coimbra, 2000. Disponível em:< www.aps.pt/ivcongressoactas/acta198pdf>. Acesso em 30 jul 2017.

SARLET, Ingo Wolfgang. Dignidade da pessoa humana e direitos fundamentais na Constituição Federal de 1988. 5.ed. Porto Alegre: Livraria do Advogado, 2007.

SILVA, José Afonso da. Direito ambiental constitucional. 5. Ed. São Paulo: Malheiros, 2004.

SILVA, José Antônio Ribeiro de Oliveira. A saúde do trabalhador como um direito humano: conteúdo essencial da dignidade humana. São Paulo: LTr, 2008.

SILVA, Michelle Emanuella de Assis. Direito à Saúde: Evolução histórica, Atuação Estatal e Aplicação da Teoria de Karl Popper. Revista Constituição e Garantia de Direitos, vol. 9, n.2, p. 4-22, ago.2017.

SIRVINKAS, Luís Paulo. Manual de Direito Ambiental. 14 ed. São Paulo. Saraiva, 2016.

ROCHA, Julio Cesar de Sá da. Direito Ambiental do Trabalho: mudança de paradigma na tutela jurídica à saúde do trabalhador. 2.ed. rev. e atual. São Paulo: Atlas, 2013.

TIBALDI, Saul Duarte, SILVA, Edilson Rosendo da. Aspectos da Proteção Rural Sob o Prisma do Princípio da Prevenção. Disponível em: <http://www.publicadireito.com.br/artigos/?cod=51624edfeb2ba95f $>$. Acesso em 12 jul 2017.

WANDELli, Leonardo Vieira. O Direito Humano e Fundamental a Trabalho: fundamentação e exigibilidade. São Paulo: LTR, 2012.

ZIMMER KNAPIK, Márcia Carneiro. O Trabalho Humano: das sociedades comunais ao modo de produção feudal. Caderno 2 da série "História Social do Trabalho". 2 edição. Curitiba. 2005. Disponível em: <http://www.cefuria.org.br/files/2012/08/cartilha2.pdf>. Acesso em 12 jul 2017. 


\title{
ENVIRONMENT OF WORK AND MENTAL HEALTH: AN INTEGRATION NECESSARY TO THE EFFECT OF THE CONSTITUTIONAL GUARANTEE TO A HEALTHY LABOR ENVIRONMENT
}

\begin{abstract}
The article through the method of bibliographic and documentary research investigates how the legal order of the country has protected the mental health risks of workers, and consequently whether or not it has been given to its constitutional guarantee the effectiveness of the constitutional guarantee to a healthy work environment. a reflection on the evolution of human work, the health of the normative construction on which the current constitutional protection of the environment, and consequently of the working environment, and the right to health were developed. Health protection can be analyzed from two dimensions: a physical and a psychic. Although occupational mental illnesses have increased significantly in recent decades, the legal protection of psychosocial risks is ridiculous compared to the legal protection of other risks that can be found in the workplace. It is concluded that it is necessary not only to formulate a more specific and contemporary regulation on the subject, but there is the emergence of the proposal of continuous and systematic measures that subsidize actions of health surveillance of the worker both by the work organizations and by the State, in order to ensure the guarantee of workers to carry out their activities in an entirely healthy environment.
\end{abstract}

Keywords: Work environment. Mental health. Constitutional Guarantee. 